\title{
OBSERVATIONS ON THE NORMALLY DEVELOPING KNEE
}

\author{
ISIDORE COHN, M.D. \\ Professor of Clinical Surgery, Tulane University of Louisiana \\ School of Medicine
}

NEW ORLEANS

Since the original study of this series proved that there are so many possible sources of error from lack of proper appreciation of the appearance of normal joints at all ages, effort has been made to study the hip, knee and shoulder in a manner similar to the methods adopted in studying the elbow. The fact that there are more sources of error in interpreting the elbow than in any other joint in the body encouraged further study.

Francis Howard Williams, in 1902, made the following statement: "The $x$-rays are of assistance in pointing out delayed union of the epiphyses and when we are familiar with the appearance to be expected of the epiphyses at different ages-that is to say, when we have made a physiological scale, we may find that we have gained a method of estimating the general condition of the younger patients in regard to their development." 1

In the light of the foregoing statement, made twenty years ago, it is remarkable that no such systematic study has heretofore been published.

We can arrive at some idea of how varied are the ideas relative to the knee by quotations from the best authorities of different periods.

Jonathan Hutchinson may fairly be expected to express the best thought of his time on the subject. In a lecture before the Royal College of Surgeons, in 1894, he ${ }^{2}$ states, in regard to the lower epiphysis of the femur, "There is no epiphysis of so much practical importance as the lower epiphysis of the femur. . . . Theoretically, we might expect a separation to occur beyond the twentieth year. The epiphysis includes the whole articular surface, and its separation must imply injury to the synovial membrane." Hutchinson further calls attention to several valuable points which should be kept in mind by a surgeon dealing with this joint in the young: the adductor tubercle is at the upper limit of the epiphysis, and both heads of the gastrocnemius are attached to the epiphysis. Another statement is made, which is interesting in a general way, if not particularly bearing on the point in hand: "It was far easier to separate the epiphysis than to rupture the liga-

1. Williams, F. H.: Roentgen Rays in Medicine and Surgery, 1902, p. 459.

2. Hutchinson, Jonathan: Brit. M. J., March 31, 1894. 
ments of the knee." When we compared the work of Hutchinson witl that of Ross and Taylor, during the past ten years on sprains, we can appreciate how keen the observations of men like Hutchinson were. Another several years, and the infrequency of sprains will be appreciated.

J. Hogarth Pringle ${ }^{3}$ states: "One (center) for the lower extremity (femur) appears shortly before birth and fuses with the diaphysis about the twentieth year. . . . In the tibia, the upper epiphysis, from which both the tuberosities and the tubercle are developed, begins to ossify at birth and joins the diaphysis at from the twenty-first to the twenty-fourth year. . . . There is sometimes a separate center for the anterior tubercle which shows at the eleventh or twelfth year.

In the fibula, the upper epiphysis begins to ossify about the fourth year and joins the shaft at the twenty-second to the twentyfourth year." Reference to texts on the subjects of the appearance, development and ossification of the epiphyses of the knee is of interest. Quotations from some of the foremost texts will be of service.

In Gray's "Anatomy" it is stated that ossification appears within the lower epiphysis of the femur during the ninth month of fetal life, and is not complete within this center until the twentieth year; further, concerning the development of the patella, that this occurs from a single center which makes its appearance about the third year; that more rarely, this bone is developed by two centers placed side by side, and ossification is completed about the age of puberty.

In speaking of the tibia, it is stated that the center for the upper epiphysis appears before or shortly after birth; it is flattened in form and has a tongue shaped process in front which forms the tubercle; and the upper epiphysis of the tibia joins the shaft about the twentieth year.

In Piersol's "Anatomy," the statement is made that the lower epiphysis of the femur is joined by the age of 20 and often earlier; the patella is not fully formed until after puberty-perhaps not before the age of 18 ; the center of ossification for the upper end of the tibia appears usually during the last month of pregnancy; and the upper epiphysis extends farther down in front, to form the tubercle, which may have a separate nucleus. According to Rambaud and Ranault, this is the usual occurrence, appearing at from 8 to 14 years, and quickly joining the epiphysis, and the upper epiphysis joins the shaft at about 19 or 20 years of age.

Scudder in his textbook on fractures says: "The lower epiphysis of the femur, the largest epiphysis of the body, appears shortly before birth, attains a good size by 2 years of age, and unites with the diaphysis at from the twentieth to the twenty-third year." He states regarding

3. Pringle, J. Hogarth: Fractures, 1910, p. 154. 
the tibia: "The epiphysis of the upper end of the tibia appears at about the first year and unites to the shaft at the twentieth to the twenty-second year."

Cotton, in his work on "Joint Fractures and Dislocations," avoids mention of the age at which ossification of the epiphyses of the lower end of the femur and the upper end of the tibia takes place.

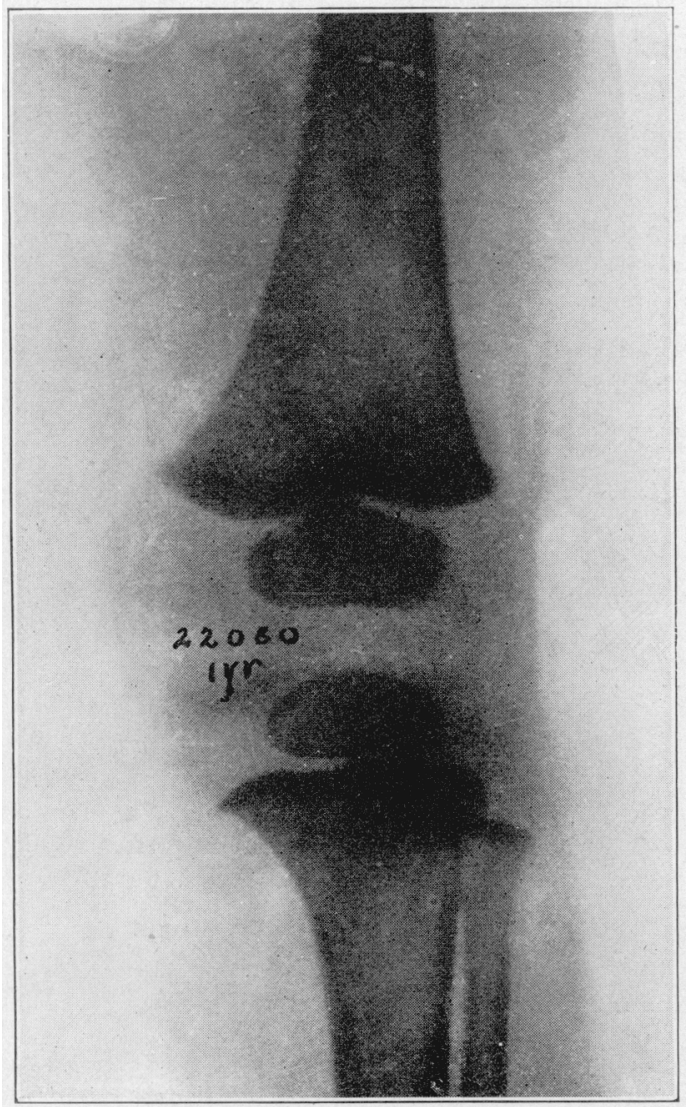

Figure 1

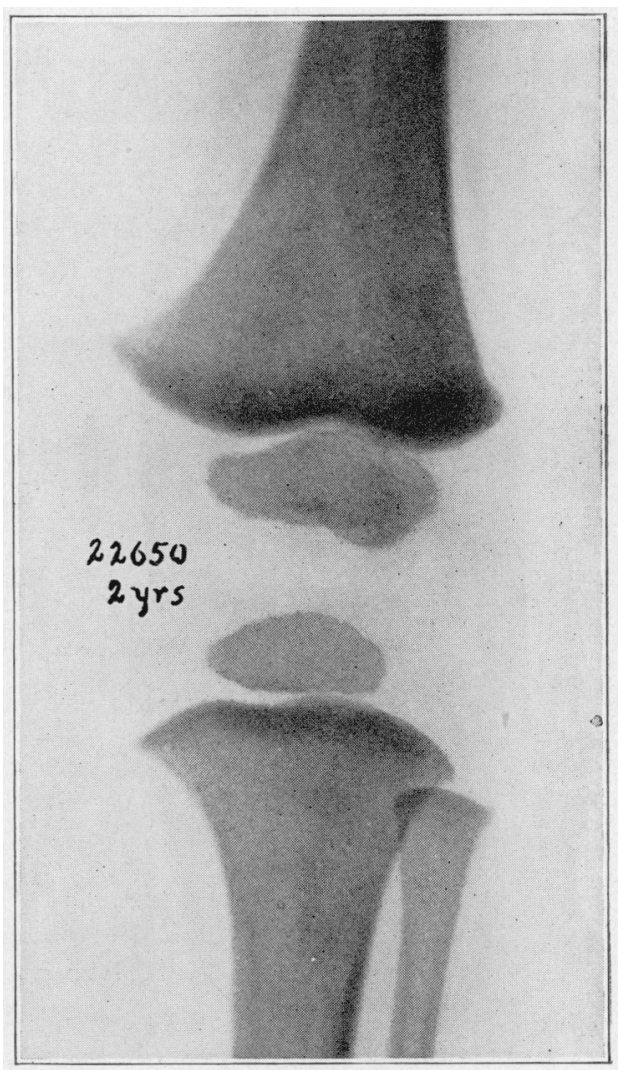

Figure 2

Fig. 1.-Normal knee, age 1 year.

Fig. 2.-Normal knee, age 2 years

Roberts and Kelly write: "The lower epiphysis of the femur includes the entire articular surface of the lower end of the bone. It is the largest epiphysis of the body, and unites with the diaphysis from the twentieth to the twenty-first year. . . . The tubercle and upper epiphysis of the tibia ossify from a single centre, and unite with 
the diaphysis from the twenty-first to the twenty-second year. The tubercle at first is cartilaginous, and ossification extends downward from the epiphysis as a long tongue-shaped projection."

\section{OBSERVATIONS}

From a review of the literature, it would seem that all are agreed that the lower epiphysis of the femur appears before birth; but there does not seem to be a unanimity of opinion as to the time of complete ossification and union with the shaft. Such statements as "about the twentieth year or earlier, twentieth to twenty-third year, and up to the twenty-fifth year" are found in the anatomies and texts commonly referred to.

From our observations, it seems justifiable to state that complete ossification and union of the lower epiphysis of the femur with the

Table 1.-Opinions Regarding Time of Ossification of Upper EPIPHysis of Tibia

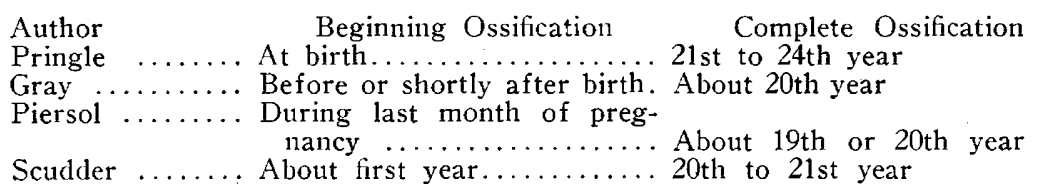

TABLE 2.-Opinions Regaruing Time of Ossification of Lower EPIPHYSIS OF THE FEMUR

\begin{tabular}{|c|c|}
\hline $\begin{array}{l}\text { Author } \\
\text { Hutchinson }\end{array}$ & 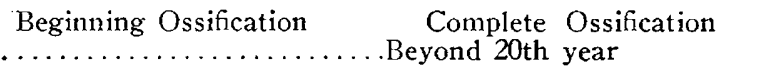 \\
\hline $\begin{array}{l}\text { Pringle } \\
\text { Gray ... }\end{array}$ & $\begin{array}{l}\text { Shortly before birth........ About } 20 \text { th year } \\
\text { Ninth month fetal life....20th year }\end{array}$ \\
\hline $\begin{array}{l}\text { Piersol... } \\
\text { Scudder } \\
\text { Cotton }\end{array}$ & $\begin{array}{l}\text { Shortly before birth } \ldots \ldots \ldots 20 \text { th year or earlier } 23 \mathrm{~d} \text { year } \\
\ldots \ldots \ldots \ldots \ldots \ldots \ldots \ldots \text { No mention made of age of } \\
\text { ossification }\end{array}$ \\
\hline $\begin{array}{l}\text { Roberts and } \\
\text { Stimson } \ldots\end{array}$ & $\begin{array}{l}\text {..20th to } 21 \text { st year } \\
\text {... Epiphysis may not unite } \\
\text { with shaft before } 25 \text { th year }\end{array}$ \\
\hline
\end{tabular}

shaft takes place between the eighteenth and nineteenth year constantly. In some instances, complete ossification and union with the shaft have taken place during the fifteenth year (Fig. 14 A), and again a similar condition has been noted during the sixteenth year (Fig. 16).

It may be argued that development occurs sooner in tropical and semitropical climates. This cannot be disputed, but it would prove interesting if our observations should be either verified or corrected for other climatic conditions.

There is a decided divergence of opinion in the literature as to the time of complete union of the upper epiphysis of the tibia. From 
Table 1 and quotations in the portion of the paper dealing with this phase of the question, it can be seen that union is supposed to take place at any time between the nineteenth and twent $y$-fourth years.

In this series of observations, the epiphyseal line cannot be made out after 18 years and 11 months (Fig. 18).

Aside from this fact, the upper epiphysis of the tibia presents several interesting phenomena which are worthy of more than passing

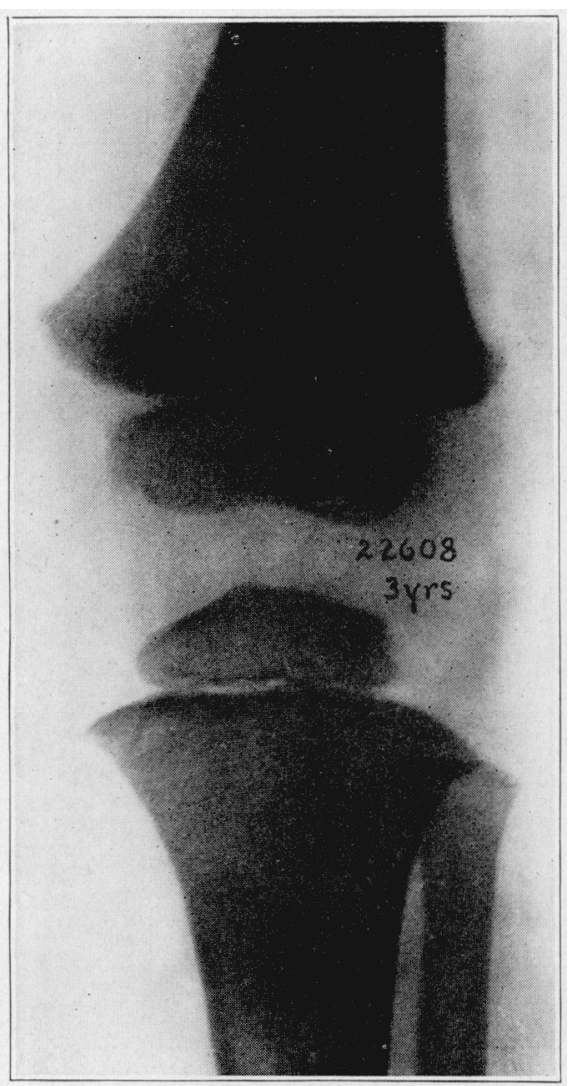

Figure 3

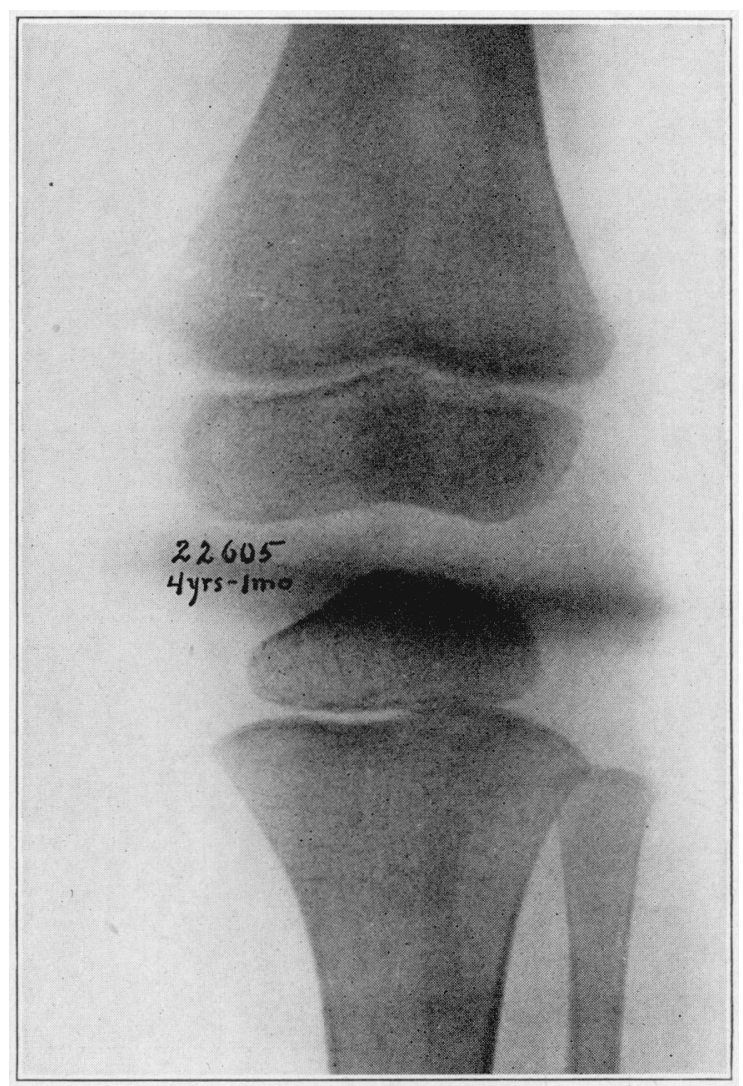

Figure 4

Fig. 3.-- Normal knee, age 3 years.

Fïg. 4.-Normal knee, age 4 years.

comment. It should be noted that normally the upper epiphysis of the tibia is in the same perpendicular planes as the lower epiphysis of the femur, and any deviation laterally should arouse suspicion that there is a displacement of one of the two.

Second and most important, the tubercle of the tibia is a clownward projection of the upper epiphysis of the tibia which makes its appear- 
ance about the eleventh year. At times the projection seems widely separated from the shaft. This maty give rise to the opinion that there is a fracture of the tubercle of the tibia, or "spur" formation. The latter was the interpretation which was made by a roentgenologist recently (Figs. $12 B$ and $14 B$ ). At times, the tubercle seems to develop from two separate centers of ossification, thus simulating a fracture within the tubercle itself (Fig. 15).

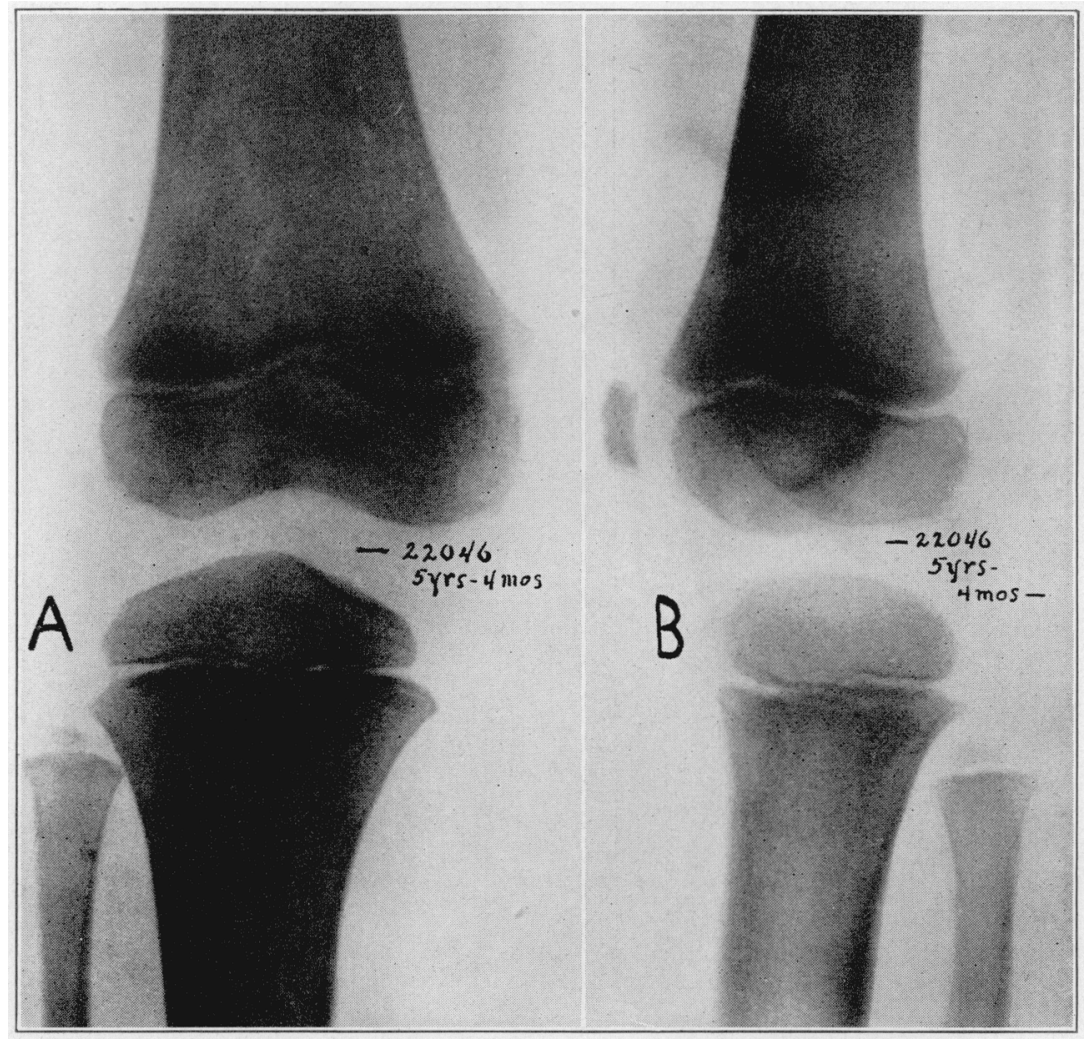

Fig. 5.-Normal knee, age 5 years and 4 months.

The tubercle is completely joined to the shaft by the nineteenth year.

The patella, according to Gray, is completely ossified "about the age of puberty." The time of the appearance of the patella is given by Gray as "about the third year."

Piersol says that it is "not fully formed until after puberty and probably not until the eighteenth year." The patella is noted in this stud $y^{\prime}$ for the first time dluring the fifth year (Fig. $5 B$ ). It makes its appearance just opposite the epiphyseal line of the lower end of the 
femur. The patella presents the most variable appearance of all structures about the linee, as evidenced by Figures $5 B, 6, A$ and 8 . At times, the patella seems to ossify through two centers within cartilage (Fig. 8). The development is progressive. but the relative position of the joints of development is unchanged; that is the midclle is opposite the original site of the epiphyseal line. It about 14 years, the patella seems to have reached its full bony development-secms because it is difficult to say what the ultimate size will be in a par-

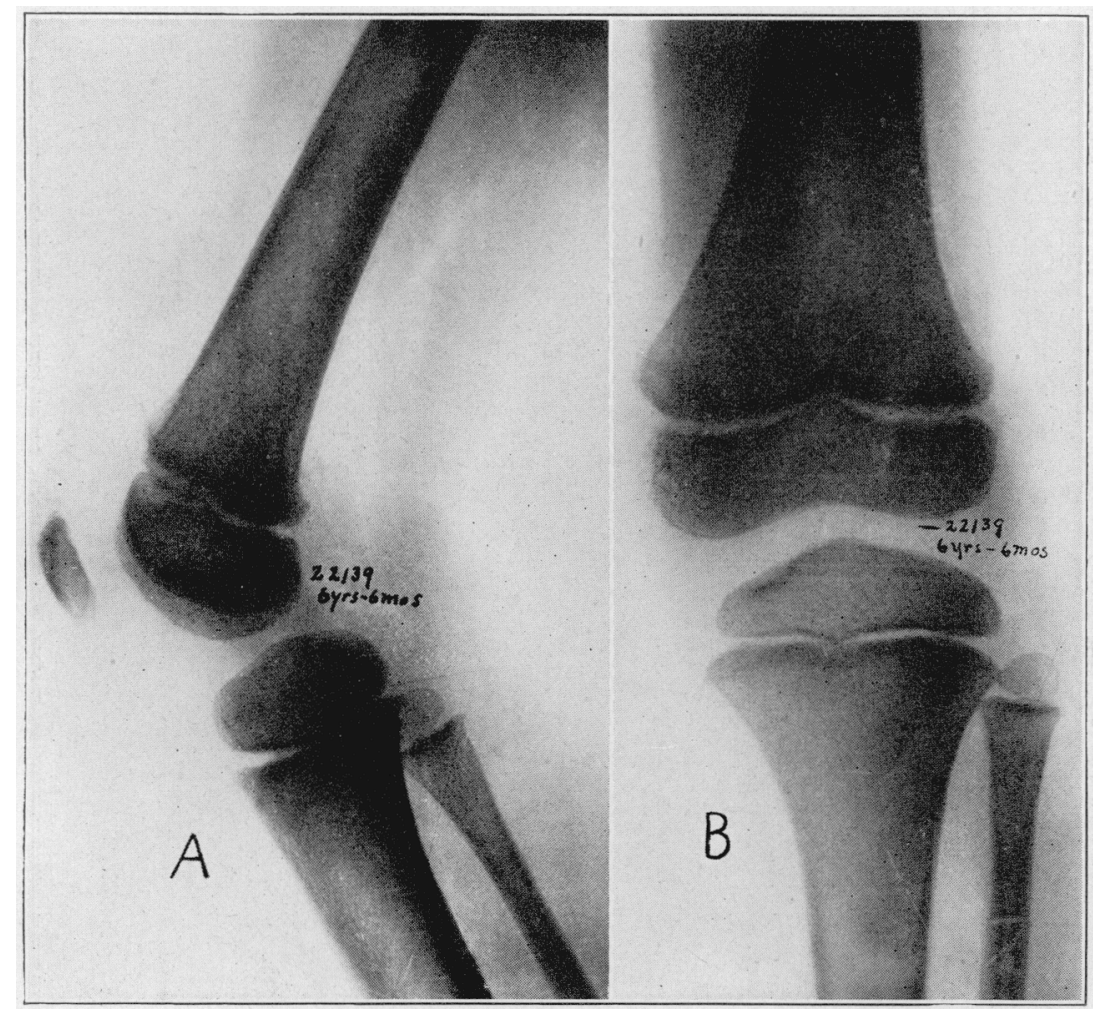

Fig. 6.-Normal knee, age 6 years and 6 months.

ticular case. It can be asserted that by this time it possesses the contour, and relative to the surrounding structures, a full development for the bone.

The upper epiphysis of the fibula is not eviclent before the fifth year. At this time, it is represented by a small rounded center of ossification stperimposed on the diaphysis of the filuta. In some instances, it has become completely ossified by the fifteenth year (Fig. 14A). This union is not constant until the end of the eighteenth year (Figs. 17 and 18). This epiphysis presents no unusual or interesting feature. 
INTERPRETATION OF ROENTGENOGRAMS OF NORMAL KNEES

At 1 year of age, there is one epiphysis for the lower end of the femur and one for the upper end of the tibia. No epiphysis of the upper end of the fibula is apparent (Fig. 1). The epiphysis of the lower end of the femur is about two thirds the size of the diaphysis, and it occupies the midplanes of the lower end of the shaft. The

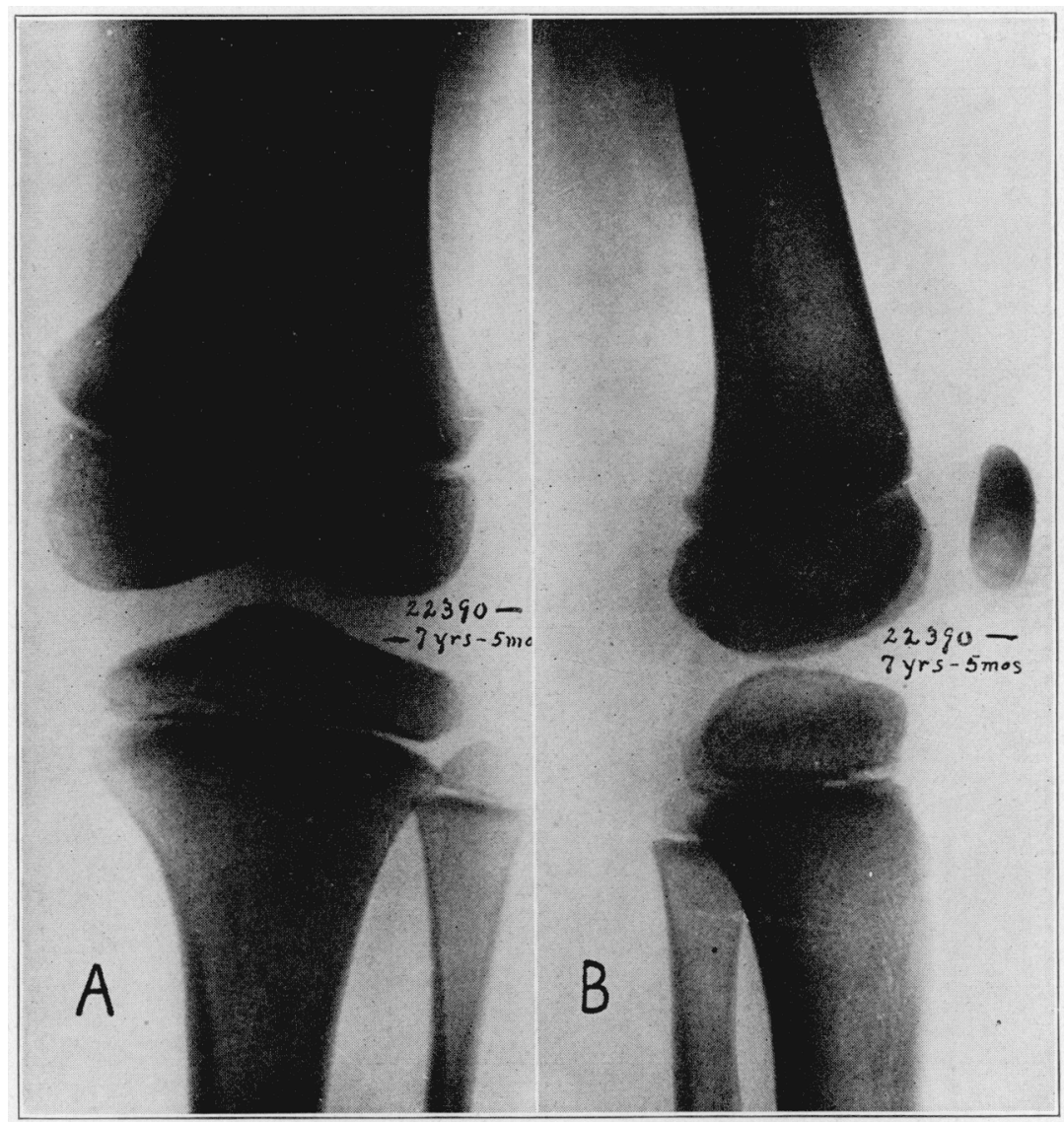

Fig. 7.-Normal knee, age 7 years and 5 months.

epiphysis of the upper end of the tibia is about the same size as that of the lower epiphysis of the fenur, and is in the same perpendicular planes roentgenologically.

At 2 years of age (Fig. 2), the appearance is similar to that at 1 year, except for a relative increase in size.

At 3 years of age (Fig. 3), the epiphyses for the lower end of the femur and the upper end of the tibia have increased relatively in the same proportion as the diaphyses. No epiphysis of the upper end of the fibula is evident at this time. 
At 4 years-of age (Fig. 4), the lower epiphysis of the femur shows marked evidence of the leveloping intercondyloid space and occupies three fourths of the lower aspect of the diaphysis of the femur. There is still no evidence of the epiphysis for the upper end of the fibula. The upper epiphysis of the tibia has not increased in the same ratio as that of the femur.

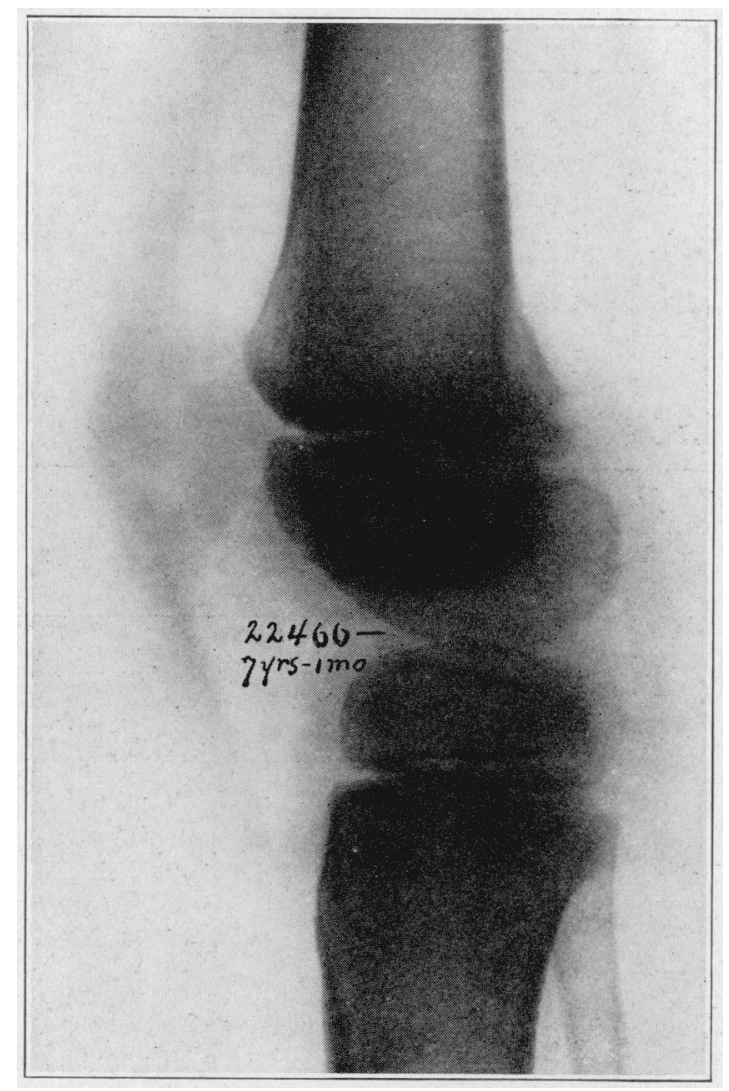

Fig. 8.-Normal knee, age 7 years and 1 month.

At 5 years and 4 months (Fig. $5 A$ ), the lower epiphysis of the femur apparently occupies entirely the lower portion of the femur. A small ossifying epiphysis is evident over the upper end of the fibula. Just at the level of the lower epiphyseal line of the femur and anterior to it, we see a small shadow of ossification within the patella (Fig. $5 B$ ).

At 6 years and 6 months (Figs. $6 A$ and $B$ ), the patella and the epiphysis for the upper end of the fibula have increased very much in size. 


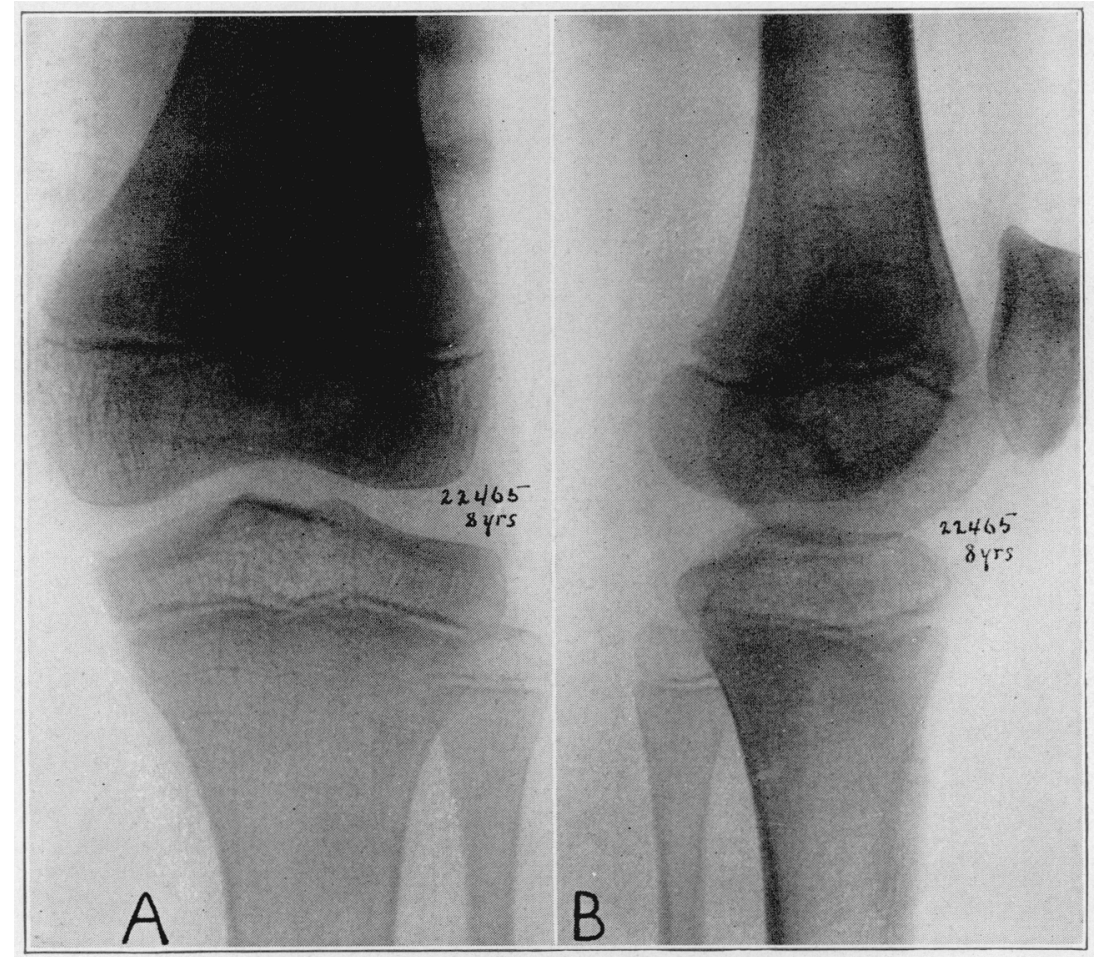

[יig. 9.-Normal knee, age $\$$ years.

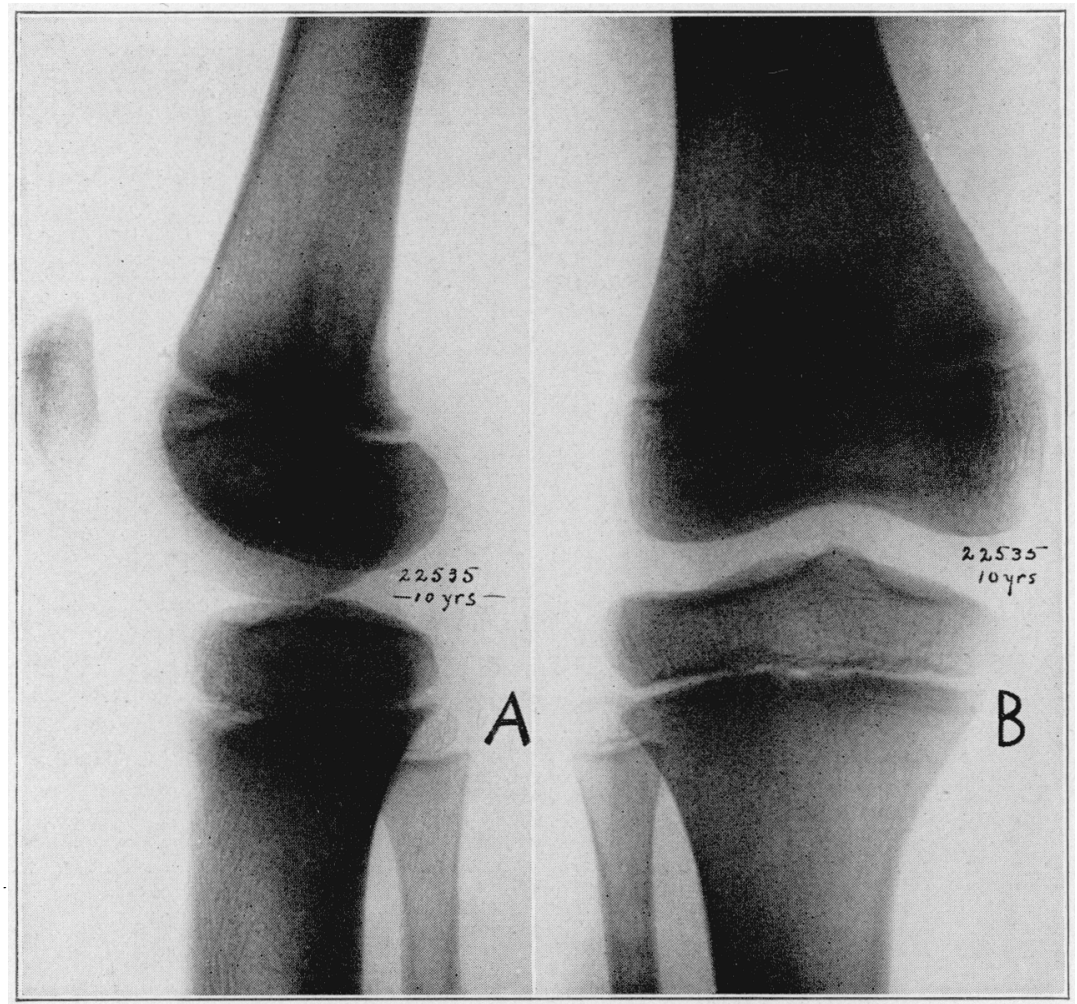

Fig. 10.-Normal knec, age 10 years.

Downloaded From: http://archsurg.jamanetwork.com/ by a New York University User on 06/24/2015 


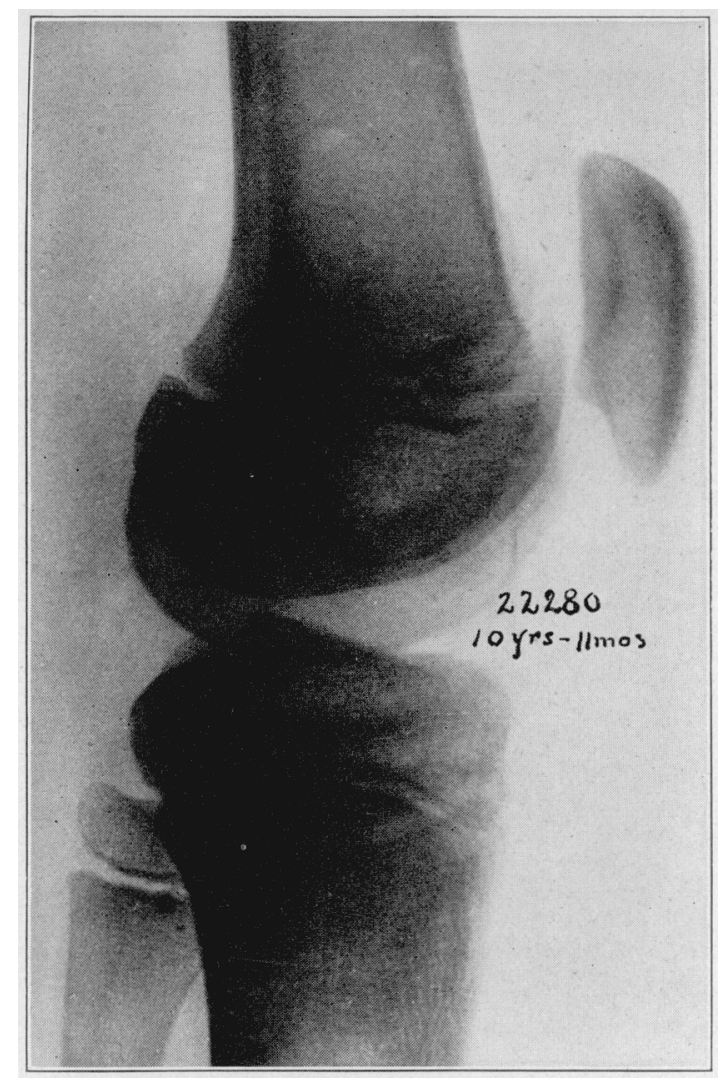

lïg. 11.-Normal knee, age 10 years and 11 months.

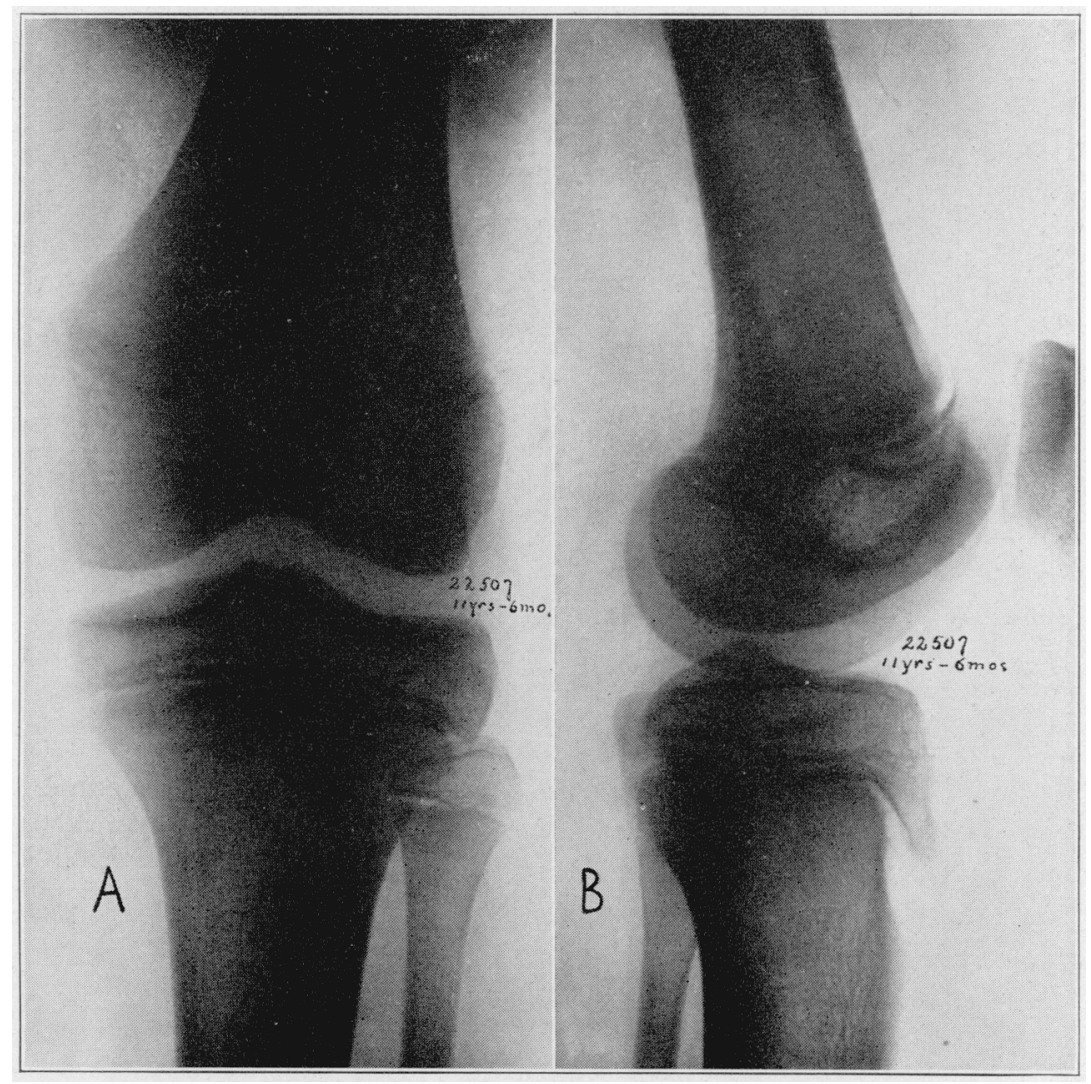

Downloaded From: http://archsurg.jamanetwork.com/ by a New York University Ứch on 06/24/2015 
At 7 years and 5 months (Figs. $7 A$ and $B$ ) all of the epiphyses have increased in size, the lower epiphysis of the femur occupying the entire lower portion of the diaphysis. The upper epiphysis of the fibula occupies two thirds of the diameter of the fibular diaphysis.

At 7 years and 5 months (Fig. $7 B$ ). the patella has ossified to a marked extent as compared to that pictured in Figure 8 , at 7 years.

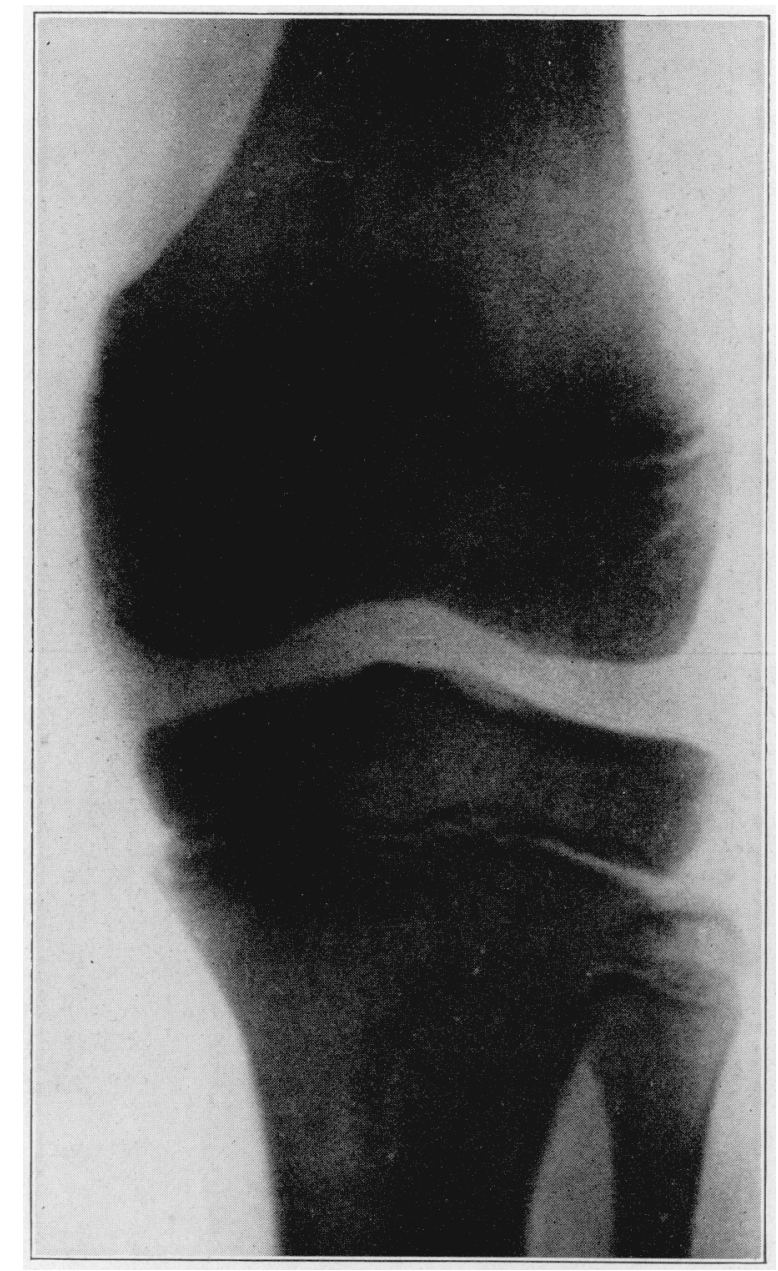

Fig. 13. - .ormal knee, age 12 years and 8 months.

There is evidence of an upward projection within the upper epiphysis of the tibia, differentiating the attachment for the crucial ligament, and also depressions for the semilunar cartilages.

The picture at 7 years and 1 month (Fig. 8) shows very slight ossification within the patella. The ossification which has taken place seems to be developing from two centers. 
At 8 years of age (Fig. $9 A$ and $B$ ), there is a marked increase in the size of the epiphyses and a closer apposition between the epiphyses and the respective diaphyses. The patella is approximately twice the size of that in the preceding picture. It is interesting to note the amount of development of the patella in the period from 6 to 8 years. At 8 years of age (Fig. $9 \mathrm{~A}$ ), for the first time, we begin to see a depression for the semilunar cartilage and evidence of spines for the insertion of the crucial ligament are evilent in the deve'oping upper epiphysis of the tibia.

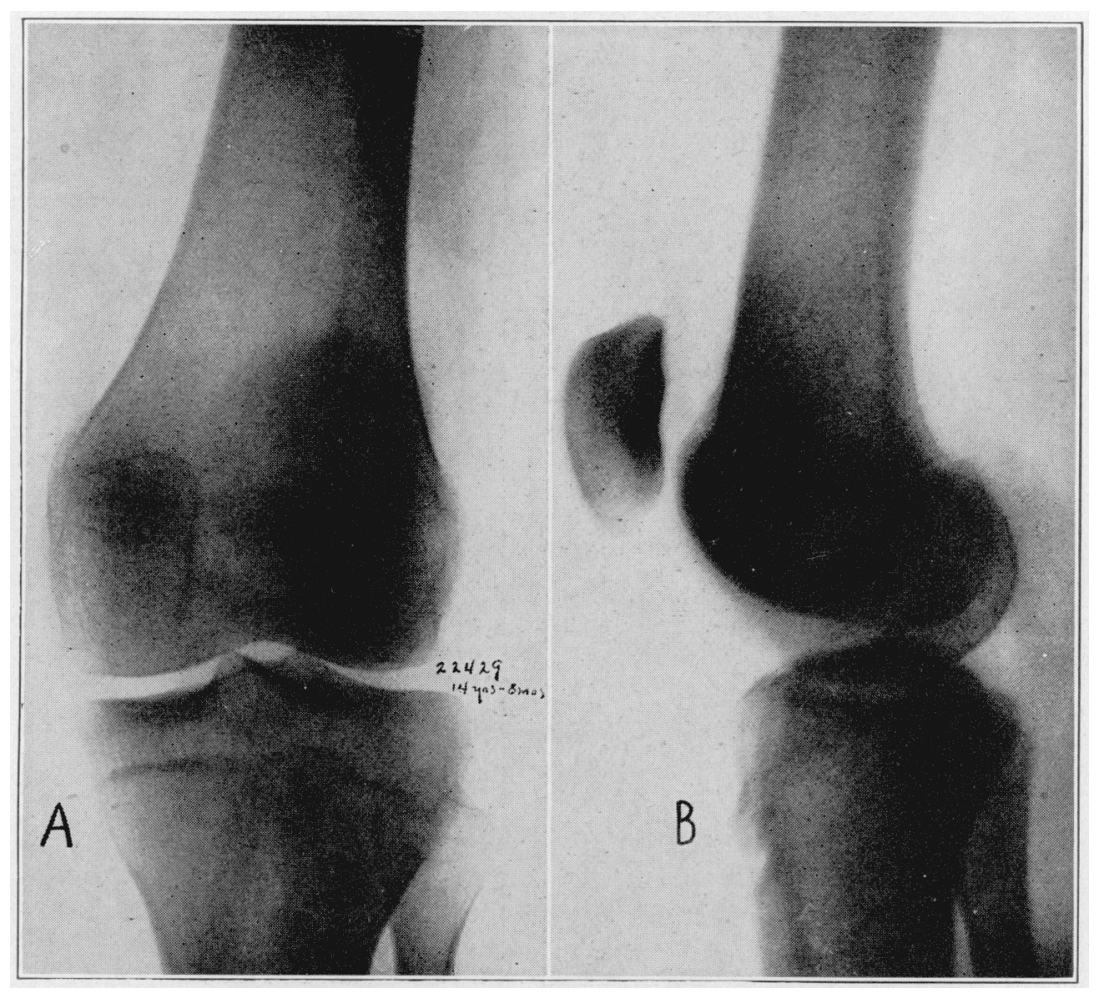

Fig. 14.-Normal knee, age 14 years and 8 months.

At 10 years of age (Fig. $10 . A$ and $B$ ). Where is a close approximation between the lower end of the femur and its epiphysis, but no true ossification has taken place between the shaft and the epiphysis. The depressions for the semilunar cartilages have deepened. There is a proportionate ossification in the upper epiphysis of the fibula and the patella. There is still no evidence of the tubercle of the tibia.

At 10 years and 11 months (Fig. 11), all of the epiphyses continue to increase in size. There seems to be a projection downward 
from the anterior surface of the upper epiphysis of the tibia, this leing the first evidence noted of the tubercle of the tibia and its origin.

At 11 years of age. little difference is shown except in the size of the epiphyses; if anything, the internal condyle seems to be larger than the external. There is no evilence of a tubercle of the tibia.

It 11 years and 6 months (Fig. $12 A$ and $B$ ), the epiphyses for the upper end of the tibia and the upper portion of the fibula are com-

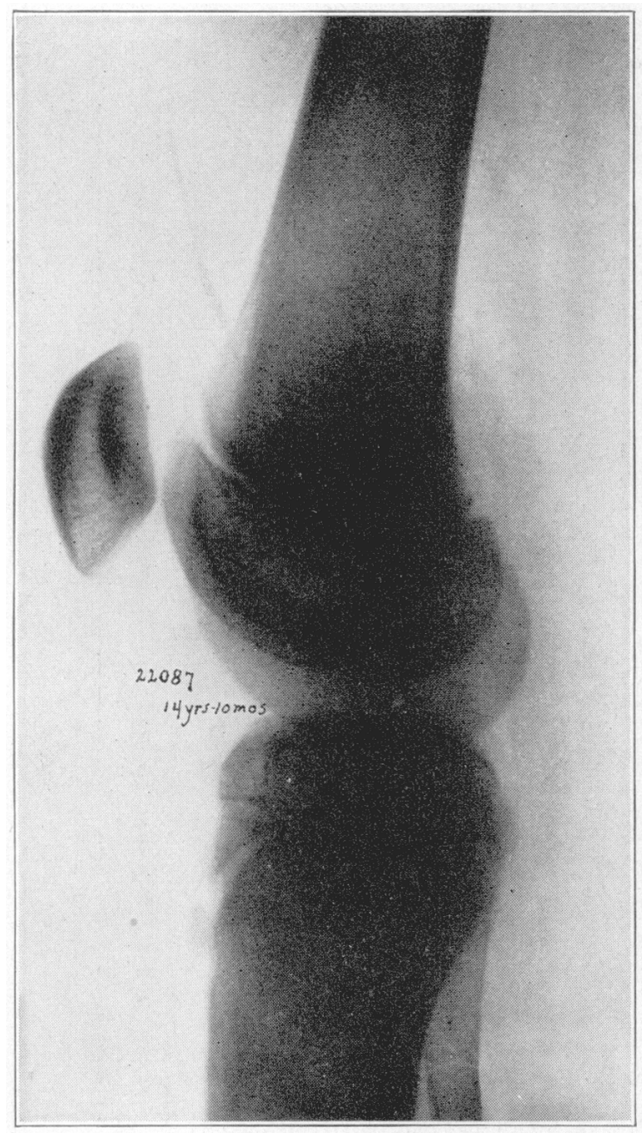

Figure 15

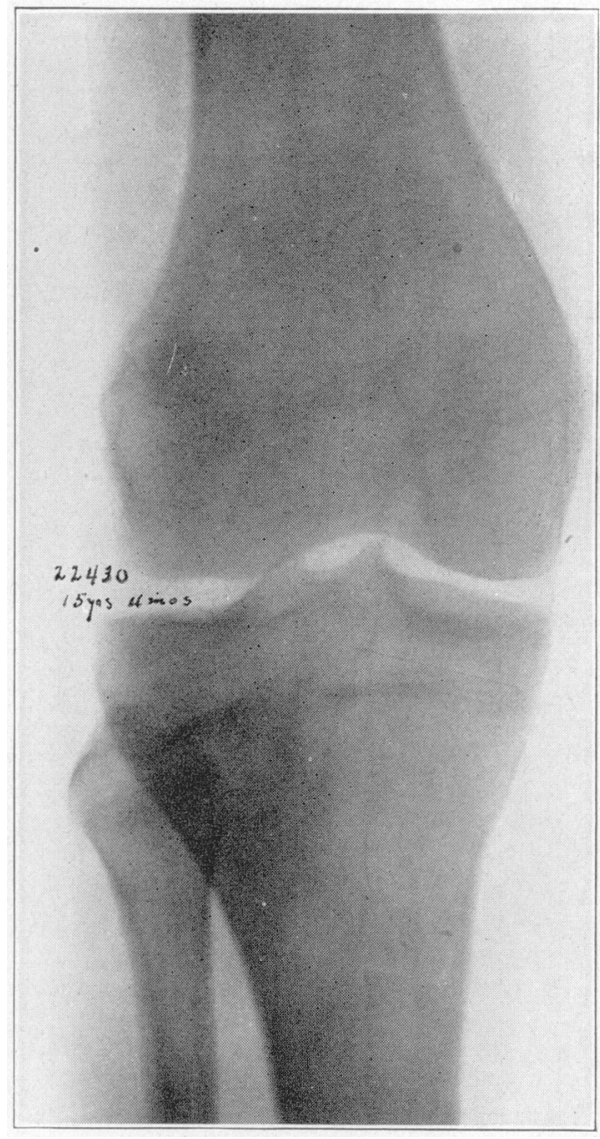

Figure 16

Fig. 15.--Normal knee, age 14 years and 10 months.

lig. 16- Tomal knee, age 15 gears and 4 months.

pletely formed, hut not mined with the shaft. There is a projection downward on the anterior portion of the libia, separated from the shaft of ahe tibia for posithly one fourth of an inch (6 mmm.). evidence of beginning asification for the tubercle of the tibia.

It 12 bears and s montls (figg. 13), a close approximation of the shaft of the tilia is noted. but no ossitication of the epiphysis and the shatl. 


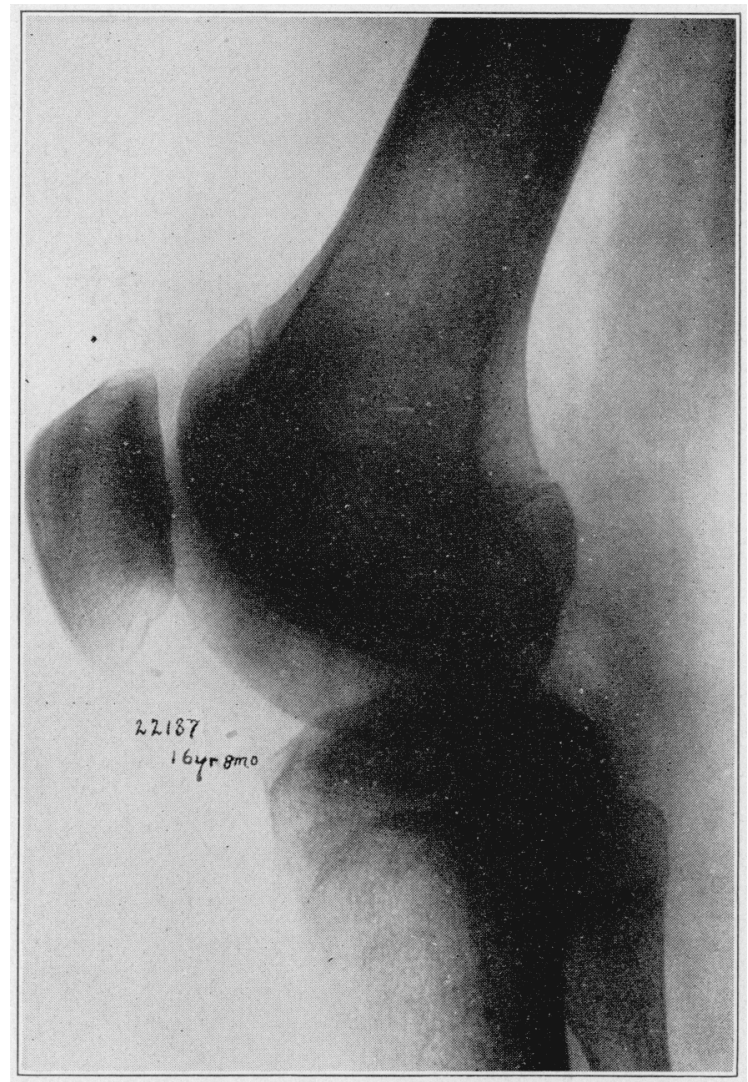

Fig. 17.-Normal knee, age 16 years and 8 months.

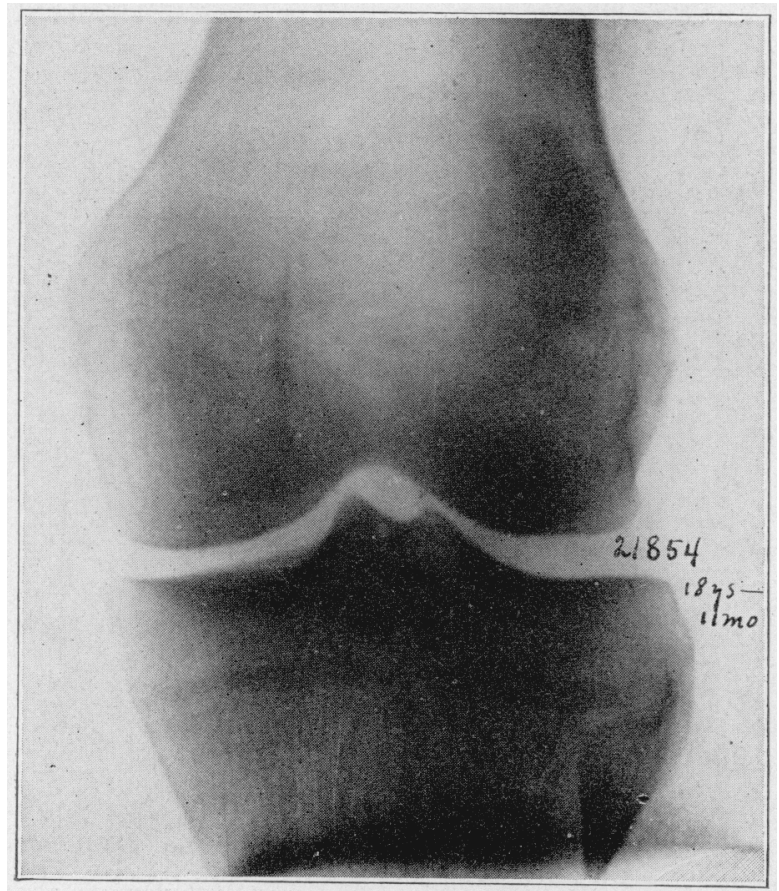

Fir. 18.-. Normai knce, age 18 years and 11 months.

Downloaded From: http://archsurg.jamanetwork.com/ by a New York University User on 06/24/2015 


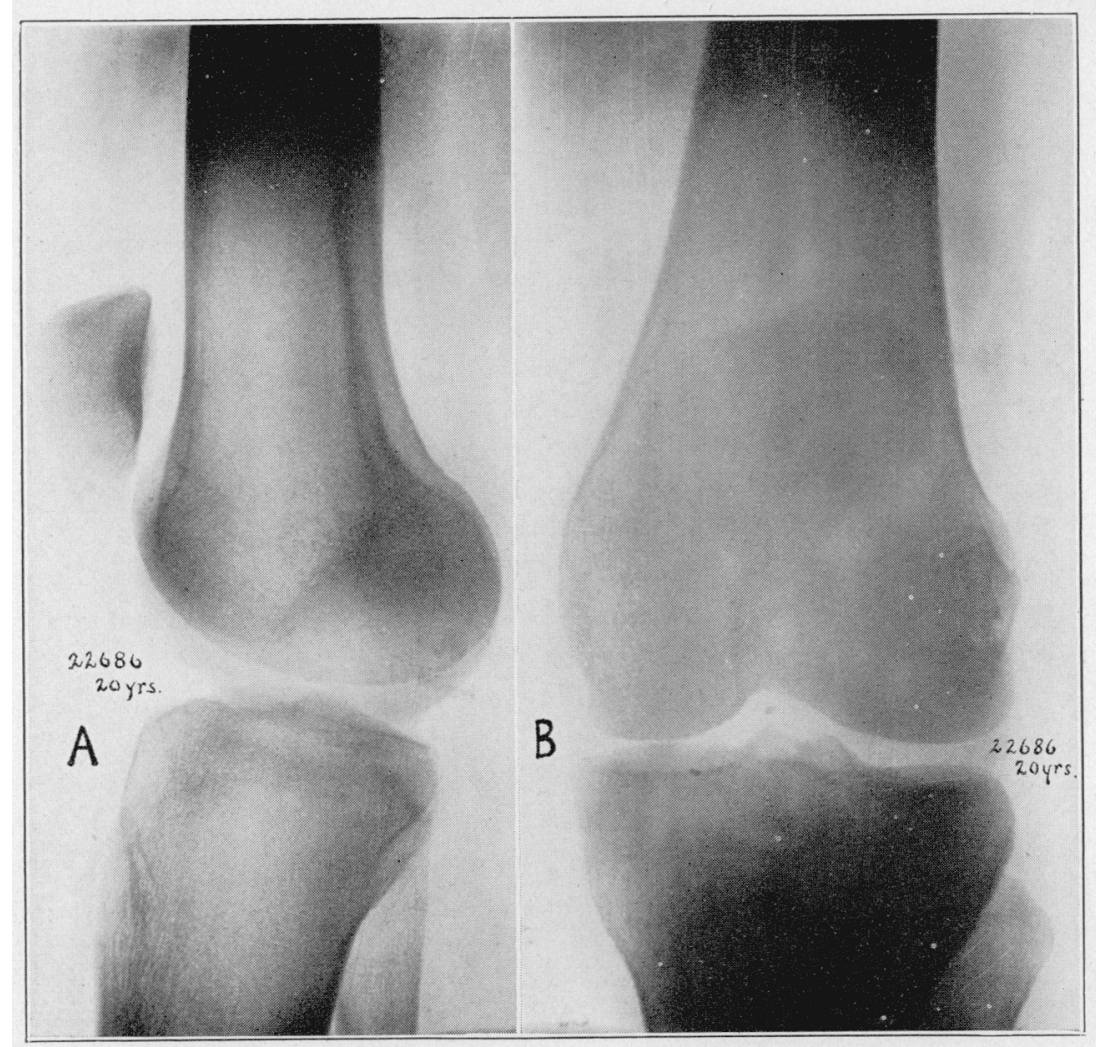

Fig. 19.-Normal knce, age 20 years.

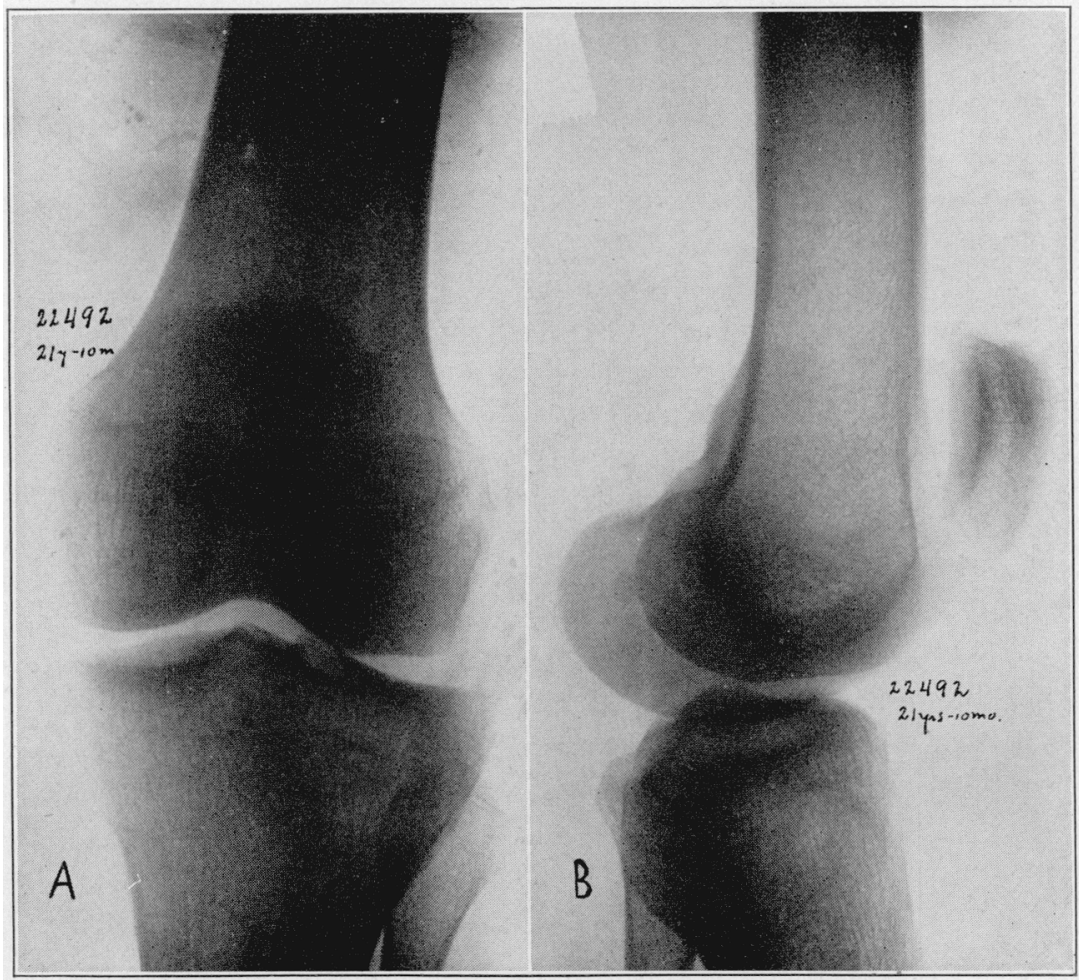

Fig. 20.-Normal knec, age 21 years and 10 months.

Downloaded From: http://archsurg.jamanetwork.com/ by a New York University User on 06/24/2015 
At 14 years and 8 months (Fig. $14 A$ and $B$ ), there is a complete cssification of all of the epiphyses of the knee. The lateral view (Fig. 14B) shows a projection downward from the upper epiphysis of the tibia, on the anterior aspect of the shaft. It is still sefarated from the shaft, but not so markedly as in preceding ages.

At 14 years and 10 months (Fig. 15) there is incomplete ossification of the shafts to the epiphyses and the tuberc'e of the tibia apparently from two centers.

At 15 years and 4 months (Fig. 16) there is a shadow, apparently the line of demarcation, but sufficiently ossified so that there is no clear space between the epiphyses and the shafts.

At 16 years and 8 months (Fig. 17), the epiphyseal lines are present. The tubercle of the tibia is almost completely ossified.

At 18 years and 11 months (Fig. 18), there is complete ossification of the epiphyses and union of the epiphyses and the shafts.

At 20 years (Fig. $19 A$ and $B$ ), there is complete ossification.

At 21 years and 10 months (Fig. $20 A$ and $B$ ), a picture similar to that at 20 years is presented.

\section{SUMMARY}

The epiphyses of the lower end of the femur and of the upper end of the tibia have attained the size of half the width of their respective diaphyses at 1 year.

There is evidence of ossification within these epiphyses at a much earlier time.

In one instance, we have a picture showing it at 7 weeks (lower epiphysis, femur).

During the first four years, no other epiphyses are evident roentgenologically.

At 5 years and 4 months (Fig. $5 \mathrm{~A}$ ), ossification has proceeded to such an extent in the lower end of the femur and upper end of the tibia that they almost cover their respective diaphyseal ends.

At this age, for the first time, one sees ossification in the upfer epiphysis of the fibula and within the patella.

During the next year, the patella increases rapidly in size. It is at this time that we notice the greatest variation in the developing patella. In one instance, at 6 years and 6 months (Fig. $6 \mathrm{~A}$ ), the patella is about one-half inch $(13 \mathrm{~mm}$.) in length, and in another picture (Fig. 8), at 7 years and 1 month, there are two small ossifying shadows within the cartilaginous patella.

At 8 years of age, the depressions for the semilunar cartilage and the spines of the tibia are evident roentgenologically.

By the tenth year, there is a close approximation between the respective epiphyses and their diaphyses. 
At 10 years and 11 months, we see the first evidence of the tubercle of the tibia. It is represented by a downward projection from the upper epiphysis of the tibia (Fig. 11).

During the twelfth year (11 years and 6 months, Fig. $12 \mathrm{~A}$ ), the tubercle increases rapidly in size, and projects forward, being separated by a wide space from the shaft of the tibia. Union between the tubercle and shaft proceeds from above down, and from before backward.

This process can be noted by referring to Figures $14 B$ and 15 .

At 18 years, this tubercle is completely ossified and united to the shaft.

In one instance (Fig. 15, 14 years and 10 months), the tubercle of the tibia seems to be ossifying through two separate centers.

At 15 years and 4 months (Fig. 16), there seems to be complete ossification within the epiphyses and union of the respective epiphyses and their diaphyses.

After the eighteenth year, there seems to be complete ossification of epiphyses and diaphyses.

1211 Maison Blanche. 